\title{
ESTADOS UNIDOS DA AMÉRICA E BRASIL: UM ESTUDO DE DIREITO COMPARADO SOBRE AS IMBRICAÇÓES NO CONTROLE DE CONSTITUCIONALIDADE
}

\author{
UNITED STATES OF AMERICA AND BRAZIL: \\ A STUDY OF COMPARATIVE LAW ON IMBRICATIONS \\ IN THE JUDICIAL REVIEW
}

ALEXANDRE COUTINHO PAGLIARINI ${ }^{1}$

AMANDA VIEGA SPALLER ${ }^{2}$

\section{RESUMO}

Primeiramente o estudo realiza um breve apanhado histórico da evolução dos precedentes judiciais nos Estados Unidos através do caso Marbury v. Madison e a importância deste caso no direito constitucional americano. Na sequência na doutrina que defende os precedentes no Brasil e seus argumentos e fundamentos para sua aplicação em âmbito interno. Desta forma, o objetivo principal do estudo é explicar as consequências que a aplicação dos precedentes judiciais pode acarretar ao Estado brasileiro se realizada da forma que está ocorrendo, ou seja, sem critérios de interpretação e sem fundamentados para sua efetiva aplicação, que pode ser prejudicial não apenas ao sistema jurídico, mas à sociedade como um todo. Logo, resta cristalina a importante utilização da interpretação fundamentada que deve ser utilizada pelos tribunais brasileiros e não simplesmente uma composição de presunções não sistemáticas do Poder Judiciário, como vem ocorrendo no cenário brasileiro.

PALAVRAS-CHAVE: Controle de Constitucionalidade. Direito Comparado. Estados Unidos da América e Brasil. Ciência da Interpretação.

\section{ABSTRACT}

First, the study gives a brief historical account of the evolution of judicial precedents in the United States through the Marbury v. Madison and the importance of this case in American constitutional law. Following on the doctrine that defends the precedents in Brazil and its arguments and grounds for its application in the

1 Pós-Doutor em Direito Constitucional pela Universidade de Lisboa. Doutor e Mestre em Direito do Estado pela PUC/SP. Professor Titular do Curso de Mestrado em Direito da UNINTER (Curitiba-PR). alexandrecoutinhopagliarini@gmail.com.

2 Mestranda em Direito na área de Poder, Estado e Jurisdição pelo Centro Universitário Internacional (UNINTER) com bolsa integral concedida pelo Programa de Pós-Graduação (PPGD), sob a orientação do Professor Doutor Alexandre Coutinho Pagliarini. Pós-Graduada em Direito Constitucional pela Academia de Direito Constitucional (ABDConst). Bacharel em Direito pelo Centro Universitário Dom Bosco (UniDomBosco). Graduada em English as Second Language pela Westchester Community College - State University of New York. Advogada. http://lattes.cnpq.br/2585671968714294. amandaspaller@hotmail. com.com. 
internal scope. In this way, the main objective of the study is to explain the consequences that the application of judicial precedents can bring to the Brazilian State if it is carried out in the way that is occurring, that is, without interpretation criteria and without grounds for its effective application, which can be harmful not only to the legal system, but to society as a whole. Therefore, the important use of the reasoned interpretation that must be used by Brazilian courts and not simply a composition of non-systematic presumptions of the Judiciary Power, as has been occurring in the Brazilian scenario, remains crystal clear.

KEYWORDS: Judicial Review. Comparative Law. United States of America and Brazil. Science of Interpretation.

\section{INTRODUÇÃO}

Quando se adentra no vasto território da busca da aplicação de precedentes no Brasil, há muito a ser analisado, desde as raízes do sistema Common Law até a forma das decisões proferidas pelos tribunais brasileiros.

Primeiro, deixe-se claro que o Brasil traz as suas tradições jurídicas do sistema que nos foi passado desde Roma, Portugal, França e Alemanha: o Brasil é e sempre foi Civil Law. Todavia, com as novidades trazidas no sistema brasileiro por conta do controle concentrado de constitucionalidade, bem como levando-se em consideração a repercussão geral, tais possibilidades propiciam ao Brasil uma atuação judicial parecida com a do Common Law. 0 problema é que ainda continuamos um país que carrega em seu dia-a-dia jurídico a tradição do Civil Law, e as possibilidades de uso de precedentes no Brasil hodierno são mais do que frustrantes, se não desastrosas.

O que se pretende mostrar aqui é como as decisões tomadas pelos tribunais brasileiros vão de contramão com o sistema Common Law. Não há fundamentações concisas, estudadas e argumentadas como é feito no Common Law e na doutrina do stare decisis. Claro que não se pode concordar que nos países que adotam tal sistema, as decisões não apresentem controvérsias e não sejam passíveis de modificação. Porém, a partir de tais decisões é que se constrói o catálogo de precedentes, e por isso mister se faz realizar uma análise interpretativa e sistemática de cada caso em concreto.

O primeiro capítulo deste artigo científico versa sobre o desenvolvimento do Common Law nos Estados Unidos e como se deu a concretização dos precedentes através do caso Marbury v. Madison e da doutrina stare decisis.

No segundo capítulo, o objetivo é mostrar a doutrina brasileira defensora dos precedentes nos Brasil, e quais os benefícios que a aplicação dos precedentes pode trazer ao ordenamento jurídico interno. Contudo, em contrapartida é realizada uma análise através de uma leitura de Lenio Streck da forma que as decisões nos tribunais são concretizadas. Através da hermenêutica, este autor critica a forma de interpretação que juízes no Estado brasileiro decidem os casos que analisam. Ou seja, o Brasil encontra-se no caminho contrário ao sistema Common Law da forma como as decisões judiciais têm sido prolatadas.

Por outro lado, é demonstrado também que com o advento do novo Código de Processo Civil, passa-se a ter o que comemorar, pois restringe-se de alguma forma a discricionarie- 
dade de atuação do judiciário, fazendo com que a utilização do princípio do livre convencimento seja diminuída, ou até mesmo extinta dos tribunais.

De forma ampla, o presente estudo não tem por fim medir se um sistema é melhor que o outro ou que os precedentes judiciais são algo que causa danos ao direito. 0 que há de se considerar aqui é a interpretação a ser realizada e os seus limites, já se concluindo, de antemão, que o limite é a Constituição.

\section{O EVOLVER DOS PRECEDENTES NOS ESTADOS UNIDOS DA AMÉRICA}

Como se sabe o sistema de precedentes é uma teoria prevista no Common Law, sistema esse que não é adotado no Brasil. Os Estados Unidos são um dos países que adotou o sistema Common Law ou ainda conhecido como anglo-saxão, raízes trazidas pelo direito inglês, visto que os Estados Unidos foram colonizados pelos ingleses. Logo, os precedentes possuem força vinculativa em seu ordenamento jurídico. Comparado ao sistema de precedentes da Inglaterra, o número de precedentes nos Estados Unidos é bem maior, independente da matéria.

Interessante analisar que diferente da Inglaterra, o Common Law nos Estados Unidos apresenta características próprias, não somente em se tratando de poder judiciário, mas sim em várias esferas organizacionais. O pluralismo organizacional é uma dessas peculiaridades do Estado americano.

O direito constitucional nos Estados Unidos não se iniciou de forma muito pacífica. Por volta do século XVII os Estados Unidos começaram a ser colonizados por ingleses que migravam para o local por diversos motivos. As colônias implantadas no novo continente eram fiéis às colônias inglesas e o governador era designado por Londres.

Em meados do ano de 1760, com a ocorrência do Stamp Act, episódio que a Coroa britânica implantou impostos em selos, jornais e demais documentos com o objetivo que suas colônias contribuíssem com sua própria defesa, apenas agravou a situação que já não se encontrava em total controle, houve grande desobediência, pois, as colônias britânicas questionavam a sua não participação nas decisões do Parlamento inglês.

Entre os anos de 1775-1788 as colônias estavam em guerra, decidindo por suas próprias independências e que consequentemente gerariam a revolução americana. Então, foi a partir de tal ato que houve o grande marco da independência americana, como explana Barroso (2013, p. 38):

Ali deliberou-se a constituição de um exército organizado, cujo comando foi entregue a George Washington; as ex-colônias foram estimuladas a adotar constituições escritas; e designou-se uma comissão para elaborar a Declaração de Independência, cujo principal relator foi Thomas Jefferson. Assinada em 4 de julho de 1776 pelos membros do Congresso, esse documento é considerado um marco na história das ideias políticas, passando a simbolizar a independência das treze colônias americanas, ainda como Estados distintos. 
Conforme o avanço dos anos, ainda havia dificuldades em ratificação pelos Estados o novo modelo constitucional. Porém, a Constituição não possuía uma declaração de direitos, que só foi introduzida em 1791, com as primeiras dez emendas, conhecidas como Bill of Rights. O Bill of Rights trouxe direitos variados que consagravam a liberdade de religião, expressão, o direito de reuniões e direitos relacionados ao devido processo legal e as condições para um julgamento justo.

A Constituição americana, comparada a Constituição do Brasil de 1988, sofreu poucas emendas e vigora a mesma até os dias atuais. A Suprema Corte americana é detentora de um papel fundamental ao constitucionalismo nos Estados Unidos através de suas interpretações.

As decisões advindas das interpretações da Corte não foram consolidadas rapidamente, tampouco suas decisões foram sempre de caráter beneficente em âmbito nacional e até mesmo em âmbito internacional. Os precedentes, característica principal do sistema Common Law, nem sempre pode se considerar que foi e ainda é aplicado nos Estados Unidos de maneira que não mereça críticas. Porém, conforme mencionado, é uma característica principal do sistema Common Law, ou seja, é a forma que o direito constitucional apresenta sua possível eficácia nos Estados Unidos.

\subsection{A DOUTRINA STARE DECISIS E O \\ DESENVOLVIMENTO DOS PRECEDENTES}

A doutrina stare decisis significa dizer que as decisões das cortes superiores passam a ter caráter vinculante para todos os órgãos inferiores de uma jurisdição. 0 instituto stare decisis possui um importante e complexo papel na construção dos precedentes no Estado americano e não está previsto de forma expressa na Constituição dos Estados Unidos, trata-se de algo oriundo do Common Law.

Contudo, importante mencionar que tal doutrina não é sinônima dos precedentes e ambas não podem ser confundidas, conforme análise de Streck (2014, p. 40);

Nesta perspectiva, não se pode perder de vista que o stare decisis é mais do que a aplicação de regra de solução análoga para casos iguais, pois essa seria uma visão muito simplificada de um procedimento altamente complexo que por séculos se estruturou naquelas comunidades.

E complementa citando que (STRECK; 2014, P.40):

(...) a doutrina stare decisis, em sua acepção técnica, surgiu apenas mais tarde, mediante uma sistematização das decisões, que distinguia a elaboração/construção (holding) e do caso que consistiria no precedente e seria vinculante para casos futuros, e o dictum, que consistia na argumentação utilizada pela corte, dispensáveis à decisão e, desse modo, não eram vinculantes.

Desta forma, o que se considera de acordo com o autor acima é que a doutrina de precedentes e a doutrina stare decisis não podem de forma alguma serem confundidas, visto que esta veio muito tempo depois daquela, e a primeira, a de precedentes, se estruturou no final do século XVII. 
Com o stare decisis as decisões da Suprema Corte Americana passam a surtir efeito vinculante, e nesses casos os juízes estão vinculados as decisões do passado, como cita Appio (2009, p.57): "um juiz pode até discordar da correção da decisão anterior, firmada no precedente e, ainda assim, terá de aderir ao que já foi decidido no passado. Nos casos de vinculação vertical, a adesão é irrestrita e obrigatória.". Nos casos de vinculação horizontal Appio (2009, p.57) explica que: "os juízes estão vinculados aos precedentes de seus antecessores e somente podem deixar de aplicar estes precedentes caso optem por revogá-los de forma expressa (overruling).".

No sistema do stare decisis, é possível os casos de overruling, ou seja, revogação de um precedente. Para que o overruling seja aplicado se faz necessária a observância de critérios pertinentes para a revogação do precedente.

Novamente nas palavras de Appio (2009, p.60):

Importante que se agregue a informação de que o overruling não pode ser invocado por uma Corte ou juízo inferior com a finalidade de revogar uma decisão de uma Corte Superior e que os precedentes da Suprema Corte dos Estados Unidos - porque órgão máximo do Judiciário norte-americano somente podem ser revogados pela própria Suprema Corte (ou pelo Congresso).

Então, percebe-se a importância da análise do caso e a fundamentação tanto para a construção, quanto para a desconstrução de um precedente judicial.

\subsection{CASO MARBURY V. MADISON COMO CONCRETIZAÇÁO DOS PRECEDENTES CONSTITUCIONAIS NOS ESTADOS UNIDOS}

No Estado americano, havia a experiência com os precedentes, mas não em esfera de direito constitucional. A aplicação de precedentes constitucionais nos Estados Unidos não se solidificou junto com a chegada do sistema Common Law americano, pois para que uma doutrina de precedentes se consolidasse, era necessário haver prévias decisões. O stare decisis também custou para se consolidar, principalmente relacionado às decisões constitucionais, como analisa Sarlet (2012, p. 884-885):

É certo que a doutrina americana demorou para individualizar os precedentes constitucionais - isto é, os precedentes que tratam de questões constitucionais - diante dos precedentes da Commom Law e de interpretação legal. É provável que isso tenha ocorrido em virtude de a jurisdição constitucional representar algo absolutamente novo para os juristas das origens do sistema judicial americano. Havia experiência com os precedentes do Commom Law, mas não com os precedentes constitucionais. A doutrina precisou de tempo - quase um século - para desenvolver uma teoria capaz de esclarecer as relações entre as diferentes espécies de precedentes.

O direito constitucional nos Estados Unidos se concretiza com o famoso caso Marbury v. Madison, e em que pese não haver a previsão do controle de constitucionalidade no Estado americano, foi com este caso que o controle de constitucionalidade americano surge e logo em consequência, consolida-se o primeiro precedente. 
O caso Marbury v. Madison é um grande marco no direito constitucional dos Estados Unidos e sempre será importante descrevê-lo quando adentra a extensa senda de precedentes, principalmente quando se trata de controle de constitucionalidade. 0 Brasil também passou a fazer uso de tal instituto quando se aborda as normas que não se apresentam em consonância com a Constituição Federal de 1988.

A decisão através da interpretação da Suprema Corte no caso Marbury v. Madison, é uma decisão que não deve ser analisada de forma isolada, visto a sua importância para todas as esferas institucionais americanas. No ano de 1801, John Adam, o presidente do país na época, estava chegando ao fim de seu mandato e indicou alguns juízes que eram aliados ao seu partido para ocupar cargos disponíveis no judiciário federal, e dentre os indicados encontrava-se Willian Marbury.

Ocorreu que não houve tempo hábil para Marbury iniciar no novo cargo, pois Thomas Jefferson que era em tese contra John Adams politicamente, tomou posse como presidente, nomeando James Madison como Secretário de Estado. Madison quando analisou a situação das nomeações realizadas por Adam, percebeu que a maioria dos juízes não tinham recebido a carta de nomeação e por tal fato resolveu cancelar o ato do ex-presidente pois o ato não estaria completo.

Marbury não conformado com a decisão de Madison, protocolou um pedido na Suprema Corte, writ of mandamus, previsto no Judiciary Act, para que as nomeações do ex-presidente fossem mantidas pelo novo presidente, pois acreditava que havia um direito potestativo de se tornar um magistrado. O Executivo foi citado para que apresentasse defesa, porém nada fez.

John Marshall que já havia sido Secretário de Estado no governo de Adam, e neste momento ocupava o cargo de presidente da Suprema Corte, se viu em uma situação completamente difícil de se resolver. Se ordenasse que Jefferson empossasse Marbury, não teria como implementar o comando; a Suprema Corte seria desmoralizada. Se desse razão a Jefferson, sem que ele tivesse se defendido, pareceria temeroso, fraco; a Suprema Corte sairia da contenda desmoralizada também. (GODOY; 2004, p.65).

Foi então que em 1803 Marshall com sua grande habilidade reconheceu que Marbury tinha direito a nomeação da magistratura vez que tratava de preencher interesse público. Contudo, ainda fundamentou sua decisão de que o dispositivo que Marbury utilizou para fundamentar seu pedido, tratava se de dispositivo inconstitucional, ou seja, era nulo, portanto, a Suprema Corte não tinha legitimidade para apreciar o pedido de Marbury.

Deste modo, podemos analisar na explanação de Maciel (2006, p.40):

(...) muito embora não se pudesse extrair do dispositivo em questão, de modo inquestionável, a competência originária da Corte para julgamento do writ aforado por Marbury e outros, Marshall, de modo subreptício e altamente engenhoso, disse que a seção 13 da Lei Orgânica atribuía inconstitucionalmente competência à Suprema Corte para julgar o writ.

Na interpretação de Marbury, o Judiciary Act não se encontrava de acordo com a Constituição, e como Marshall entendia pela hierarquia das normas constitucionais, as normas infralegais que não estivessem em consonância com a Constituição não teriam validade, logo, declarou o artigo do Judiciary Act que Marbury utilizou, como inconstitucional, reali- 
zando pela primeira vez o controle de constitucionalidade e o primeiro precedente nos Estados Unidos. Assim, diante de tal decisão não entrou em conflito com o então atual presidente Thomas Jefferson, não deixou de dar razão a Marbury e ainda poupou a Suprema Corte de proferir decisão que pudesse prejudicar e vexar a si própria.

Analisando a perspectiva de precedentes a partir do caso citado, percebe se que em que pese os Estados Unidos ser regido pelo sistema Common Law, a lei posta não é deixada de lado, pois o juiz Marshall interpretou e decidiu optando pela hierarquia constitucional, ou seja, pela prevalência da Lei Maior, mesmo que esta não dispusera de controle de constitucionalidade. Assim, pode se entender de acordo com Farnsworth (1963, p.72) que: "os Estados Unidos possuem seu sistema próprio de legislação, porém os juízes encontram-se nos tribunais não para modificar os estatutos, ou seja, a legislação, mas sim para decidir conforme a lei existente através da interpretação.".

Veja-se de forma mais detalhada:

Embora a interpretação dos estatutos suscite algumas questões peculiares ao sistema jurídico americano, muitos dos fundamentais são familiares ao sistema legal. De início, é axiomático que, entre a corte e a legislatura, o comando da legislatura seja supremo, exceto, com certeza, no ponto de validade dos próprios estatutos. A jurisprudência pode ser e muitas vezes é alterada por lei, mas, pelo menos em princípio, os estatutos não podem ser alterados por decisão judicial. A função do tribunal é lidar com a legislação é a da interpretação. Quanto a natureza e limites dessa função, no entanto, não há acordo universal. (tradução livre). ${ }^{3}$

Assim, com a consolidação dos precendentes constitucionais no Estado americano a partir do importante caso Marbury v. Madison entende-se que os tribunais devem interpretar e aplicar a legislação existente.

É evidente que todo o sistema de precedentes nos Estados Unidos possui lados distintos. Por um lado, encontram-se os juízes que podem ser considerados ativistas, os quais via de regra seguem as ideologias do Partido Democrata, sendo o mais ativista o juiz Earl Warren, porém este, indicado pelo presidente da época que pertencia ao Partido Republicano. Nesta fase, entende-se que a Suprema Corte proferiu decisões digamos que progressistas na história dos Estados Unidos.

Já por outro lado existe os juízes considerados como textualistas, originalistas, que entendem que as interpretações devem ser realizadas de forma literal com o texto da Constituição. Após a morte de Willian Rehnquist, o atual o presidente da Suprema Corte dos Estados Unidos é John Roberts, que foi indicado pelo presidente George W. Bush no ano de 2005. Roberts é republicano e possui e uma tendência bastante conservadora.

$\mathrm{Na}$ fase de conservadorismo que atualmente se vive a Suprema Corte dos Estados Unidos, aos poucos as decisões alcançadas pela forma de pensar da Corte estabelecida anteriormente, a conhecida como Corte de Warren, vai se transformando cada vez mais conservadora.

3 Although the interpretation of statutes raises some questions which are peculiar to the Americam legal system, many of the fundamental are familiar to the most legal system. To begin with, it is axiomatic that as between the court and the legislature, the command of the legislature is supreme except, to be sure, on the point of validity of the statutes itself. Case law can be and often is altered by statute but, at least in principle, statutes cannot be altered by court decision. The court's function is 
Apenas a título de demonstração de como a Corte Americana está em consoante mudança, em 1989 com Rehnquist na presidência, com o caso Webster v. Reproductive Health Service, houve grande restrição para as práticas do aborto.

Alguns anos antes de Robert assumir a presidência da Corte em 2005, ele escreveu um documento solicitando que a decisão tomada em 1973 em que foi decidido a legalidade do aborto, o caso descrito suscintamente acima, fosse revogada. Porém, sem sucesso. É certo que há divergências entre os estados americanos, mas em geral os Estados Unidos não criminalizam o ato.

Em que pese ser um sistema jurídico oriundo do Estado americano e uma "herança" do sistema Common Law Inglês, o que se percebe sem dúvidas é o ativismo judicial no momento de interpretação da Carta Magna americana que encontra-se em vigor desde 1789. É óbvio que em todos os anos de atuação da Suprema Corte dos Estados Unidos, houve muitas mudanças positivas para o próprio Estado e consequentemente para o Brasil, visto que em grande parte o modelo judicial brasileiro é pautado no modelo americano. Contudo, é de mais relevância ainda analisar tais decisões e perceber até que ponto pode se chegar com interpretações e opiniões judiciais em casos concretos. Ou seja, há uma linha muito tênue entre decisões e opiniões e uma não deve ser confundida com a outra.

\section{DOUTRINAS SOBRE OS PRECEDENTES NO BRASIL}

Como se bem sabe, o Brasil adota o sistema Civil Law em âmbito jurídico, conhecido também como romano-germânico. O Civil Law possui suas origens na antiga Roma. Assim como o Common Law dos Estados Unidos se dispersou um pouco da sua origem inglesa, o Civil Law também apresenta algumas distinções de suas raízes romanas.

Diferente do Common Law, no Civil Law as leis são a principal fonte para resolução de conflitos e garantias de direitos fundamentais, estão assentadas em formas de códigos advindos do Poder Legislativo, contudo, necessitam estar em consonância com a Constituição Federal. Ainda, as leis do sistema romano-germânico, utilizadas em determinado caso concreto, não visam ser utilizadas exatamente as mesmas para a resolução de casos futuros, visto que em um sistema que a lei é predominante, não existe apenas uma correta para aplicar ao caso a ser julgado.

A ideia brasileira de controle de constitucionalidade tem matriz baiana, no pensamento de Ruy Barbosa. De fato, nos comentários à Constituição republicana de 1891, um dos seus artífices, o sempre lembrado Ruy Barbosa (1929, p. 87), ensina, sobre o controle de constitucionalidade que:

A justiça tem de conhecer-Ihes da existência, para conhecer da existência da lei. Mas não exerce, a tal respeito, a menor funcção discrecionaria. A Constituição traçou nos arts. 36 e 40 as regras de elaboração legislativa imposta aos tres factores, de cuja cooperação depende a formação legitima das leis. Si algumas dessas regras for materialmente conculcada, ou postergada, e dessa infracção flagrante se conservar a prova authentica nos proprios actos do Congresso ou do governo, destinados a attestar a deliberação, a sancção, a promulgação, lei não ha; porque a sua elaboração não se 
consumou. Os tribunaes, portanto, não podem applical-a. Em uma palavra, toda contravenção material de formas constitucionaes, authenticamente provada, no processo de elaboração legislativa, vicia e nullifica o acto do legislador. Não assim a simples violação de formas regimentaes.

A doutrina brasileira defensora dos precedentes alega que há uma grande aproximação do sistema Common Law e romano-germânico, principalmente após a vigência do novo Código de Processo Civil. Marinoni (2013, p.22), defende a aproximação dos dois sistemas e cita que existe "(...) a necessidade de se render respeito aos precedentes no direito brasileiro.". Ainda, o autor explica (2013, p.22):

Não obstante as transformações que se operaram no Civil Law-inclusive nas concepções de direito e de jurisdição, marcadamente em virtude do impacto do constitucionalismo-e as especificidades do sistema brasileiro-que se submete ao controle difuso da constitucionalidade da lei-, há notória resistência, para não se dizer indiferença, a institutos do common law de grande importância ao aperfeiçoamento do nosso direito, como é o caso do respeito aos precedentes.

Para Wambier (1997, p.80), que também é defensora da doutrina dos precedentes explana que: "Trata-se de uma conquista dos povos civilizados, que gera segurança, previsibilidade e se constitui numa defesa do sistema contra a arbitrariedade.".

Ambos os autores acreditam que os tribunais decidindo iguais a partir de um determinado caso concreto e com força obrigatória, as decisões proferidas terão um caráter mais isonômico, garantido o direito das partes de forma mais concisa. Ou seja, acreditam que os precedentes judicias trazem segurança para o sistema jurídico e que quando o sistema Civil Law é aplicado não há a garantia de igualdade para todos os indivíduos de um Estado de Direito.

\subsection{BREVE ANÁLISE DA TEORIA DOS PRECEDENTES NO CÓDIGO DE PROCESSO CIVIL DE 2015}

O novo Código de Processo Civil, não trouxe a regulamentação dos precedentes no Estado brasileiro, porém em vários de seus artigos o tema é mencionado. Há muitos anos os Tribunais Superiores estão de alguma forma tentando introduzir a prática dos precedentes, antes mesmo até da emenda constitucional $n^{\circ} 45$ de 2004 em que regulamentou o instituto das súmulas vinculantes editadas apenas pelo Supremo Tribunal Federal.

No novo CPC de 2015, BARROSO e MELLO (s/a, p.11-12) citam:

Nele se instituiu um sistema amplo de precedentes vinculantes, prevendo-se a possibilidade de produção de julgados com tal eficácia não apenas pelos tribunais superiores, mas igualmente pelos tribunais de segundo grau. Nessa linha, o art. 927 do novo Código definiu, como entendimentos a serem obrigatoriamente observados pelas demais instâncias: (i) as súmulas vinculantes, (ii) as decisões proferidas pelo STF em sede de controle concentrado da constitucionalidade, (iii) os acórdãos proferidos em julgamento com repercussão geral ou em recurso extraordinário ou especial repetitivo, (iv) os julgados dos tribunais proferidos em incidente de resolução de demanda repetitiva e (v) em incidente de assunção de competência, (vi) os enunciados 
da súmula simples da jurisprudência do STF e do STJ e (vii) as orientações firmadas pelo plenário ou pelos órgãos especiais das cortes de segundo grau.

Nos institutos mostrados acima, dois deles não eram previstos anteriormente, sendo estes os incidentes de resolução de demanda repetitiva e de assunção de competência.

A teoria dos precedentes vem ganhando corpo não somente em âmbito constitucional, mas também em âmbito processual com o advento do NCPC. Ataíde Jr. (2012, p. 363) cita que a prática dos precedentes “(...) se volta a solucionar com maior segurança jurídica, coerência, celeridade e isonomia as demandas de massa, as causas repetitivas, ou melhor, as causas cuja relevância ultrapassa os interesses subjetivos das partes".

Analisando o art. 927 do NCPC já citado acima por Barroso, no que tange os incidentes de resolução de demanda repetitiva, foi uma das maiores novidades trazidas no novo CPC. Conforme explana BARROZO e MELLO (s/a, p. 12): "O incidente de resolução de demanda repetitiva corresponde a um procedimento especial para julgamento de caso repetitivo que pode ser instaurado em segundo grau de jurisdição.". Ou seja, em análise aos artigos 976 a 987 do CPC/2015, a finalidade do instituto é para que quando instaurada uma determinada jurisprudência sobre determinada questão é viável que os tribunais de segunda instância decidam todos os casos seguintes, via de regra, de forma igual.

Com relação ao segundo ponto importante acima citado, trazido pelo artigo 927 do CPC, o incidente de assunção de competência, BARROZO E MELLO (s/a, p. 12) explicam que: "O incidente de assunção de competência possibilita que o julgamento de relevante questão de direito, com grande repercussão social, que não se repita em diferentes processos, seja apreciado por órgão específico, indicado pelo regimento interno do tribunal. ". O instituto disposto no artigo 947 do CPC/2015 prevê vários requisitos para sua admissibilidade, porém o que mais é relevante na presente pesquisa é o que cita o $\S 3^{\circ}$ - "O acordão proferido em assunção de competência vinculará todos os juízes e órgão fracionados, exceto se houver revisão de tese.". Portanto, em interpretação ao código de processo civil, Wambier (WAMBIER e outros 2015, p. 2113) citam que:

Com a intenção de impor a observância ao que definido pelo colegiado, o § $3 .^{\circ}$ do art. 947 da atual legislação expressamente prevê que a decisão vinculará todos os juízes e órgãos fracionários do tribunal. Aí, a grande distinção entre a assunção do CPC de 1973 e do CPC atual. Nada mais natural que ocorra a vinculação na medida em que o colegiado superior reconheceu a relevância da questão e a decidiu. Haveria insegurança se decisões fossem tomadas em outros processos acerca da mesma tese firmada em sentido distinto, além de um tal agir ir de encontro com a importância de se respeitar a jurisprudência de órgãos hierarquicamente superiores.

Desta forma, o que se entende de modo geral não só com a implementação dos dois institutos de forma clara no CPC, mas também com o objetivo de implantar a teoria dos precedentes no sistema judicial brasileiro é que o que se pretende buscar é a igualdade e a segurança jurídica na decisão dos casos ditos similares. Mas a questão é: será que realmente existe a igualdade e a segurança jurídica nas decisões, partindo do pressuposto que a prática dos precedentes já se encontra implantada em nosso sistema? Entendemos que não: a práxis jurisprudencial do nosso Pretório Excelso demonstra uma estupenda fragilidade da Suprema Corte brasileira na manutenção da sua própria jurisprudência, de modo que a 
Suprema Corte do Brasil julga contra si própria ao se utilizar dos novos instrumentos que lhe foram disponibilizados pela Constituição de 1988 e pelo NCPC. Instabilidade jurídica - que fere o princípio constitucional da segurança jurídica - é o que causam as liminares concedidas pelos ministros do STF, sucessivamente, umas contra as outras, quase todas elas indo em caminhos que não são os da Turma e/ou os do Plenário da Corte. Logo, é de se desconfiar que o STF, em sua atual composição, se encontra deveras politizado.

\subsection{UMA LEITURA DE LENIO STRECK - CRÍTICA HERMENÊUTICA DO DIREITO}

A doutrina brasileira defensora dos precedentes afirma que com os precedentes judiciais, a igualdade, isonomia e segurança jurídica será garantida, pois não é coerente que em casos semelhantes, os juízes utilizem de uma interpretação da lei de forma variada, ou seja, é preciso ter consolidada uma interpretação para que a igualdade seja apresentada nas decisões e fundamentações.

No Brasil, não existe a possibilidade da tradição Civil Law ser extinta para que se passe a utilizar critérios da prática Common Law. Primeiramente Streck (2014, p. 35) cita que: "(..) na tradição Civil Law, apenas é possível aferir-se a importância da jurisprudência se levarmos em conta sua relação com a lei.". Em outro momento cita também que: (STRECK; 2014, p. 52) "discutir precedentes, jurisprudência e súmulas vinculantes é, necessariamente, adentrar no delicado campo da hermenêutica. Há vários modos de trabalhar a "questão hermenêutica", que, ao fim, será a "questão hermenêutica.".

Pois bem, é certo que no sistema Civil Law os juízes não estão isentos de interpretações para se chegar na melhor decisão possível de cada caso concreto, porém existe a necessidade da interpretação estar vinculada a lei, e não um emaranhado de decisões sem a devida estrutura do direito, ou seja, um amontoado de decisões sem fundamentos, onde se decide como quer, pois, tal fato se tornaria uma espécie de arbitrariedade judicial, o que também não é aceitável no sistema Common Law. E, atualmente o que se percebe no judiciário brasileiro é este fenômeno, o qual Streck chama de solipsismo. Desta forma, podemos analisar a crítica feita pelo autor (2014, p. 330-331):

Os pré-juízos são condições de possibilidade da compreensão porque nos permite projetar sentido. Entretanto, o sentido projetado só pode se confirmar se ele for derivado de um préjuízo legítimo. Pré-juízos ilegítimos geram projetos de sentido ilegítimo e, inevitavelmente, fazem a interpretação incorrer em erro. Apenas quem suspende os próprios pré-juízos é quem interpreta corretamente. Um julgador que não consegue suspender seus pré-juízos está incapacitado para a sua tarefa.

Antes de adentrar mais profundo sobre a teoria dos precedentes judiciais na visão de Lenio Streck, mister se faz mencionar sobre a interpretação da norma a partir de um texto. A norma é a interpretação do texto, surge de um processo hermenêutico realizado pelo intérprete que aplicará o texto, em forma de norma ao caso concreto, porém mais uma vez, essa aplicação não deve ser realizada através de qualquer interpretação. 
O que transforma este fato num ato jurídico (lícito ou ilícito) não é a sua facticidade, não é o seu ser natural, isto é, o seu ser tal como determinado pela lei da causalidade e encerrado no sistema da natureza, mas o sentido objetivo que está ligado a esse ato, a significação que ele possui.

Logo, percebe-se que cabe ao intérprete da lei dar sentido ao texto em que a norma está inserida e analisá-la diante da problematização posta. Vejamos nas palavras de Grau (2006, p.35):

O intérprete discerne o sentido do texto a partir e em virtude de um determinado caso dado; a interpretação do direito consiste em concretar a lei em cada caso, isto é, na sua aplicação [Gadamer]. Assim, existe uma equação entre interpretação e a aplicação; não estamos, aqui, diante de dois momentos distintos, porém frente a ia só operação [Marí]. Interpretação e aplicação consubstanciam um processo unitário [Gadamer], superpondo-se.

Ainda, nas palavras de Streck quem afirma que a norma será sempre a interpretação do texto, vejamos (2014, p. 312-313):

Portanto, simplificadamente, é possível afirmar que, quando se fala "da norma que ex-surge do texto", não se está a falar de um processo hermenêutico-interpretativo realizado por partes (repetindo, assim, a hermenêutica clássica-primeiro conheço, depois interpreto, por fim, aplico). É evidente que não. Eu não vislumbro primeiramente o texto para depois "acoplar" a respectiva norma. A "norma" não é uma "capa de sentido", que existiria apartada do texto. Ao contrário disto, quando me deparo com o texto, ele já ex-surge normado, a partir de minha condição de ser-no-mundo.

Assim, diante da explanação entre texto e norma e entendendo que a norma é consequência da interpretação do texto, passa-se a entender a necessidade de uma interpretação coesa ao texto, e não a mera prática de solipsismo praticada por juízes. Logo, cabe pensar: se com a norma advinda de um texto expresso em uma legislação, ocorre interpretações equivocadas, como está sendo a interpretação pelos juízes nos tribunais brasileiros em casos de aplicação de precedentes judiciais com a tentativa de se igualar ao modelo Common Law? Contudo, importante lembrar que nem em um sistema de precedentes o juiz possui discricionariedade para interpretação, é necessário que se observe todo o catálogo de precedentes já existentes.

A regra do stare decisis oriunda do sistema de precedentes é a principal característica do Common Law, como já visto, e é um ponto essencial para a aplicação dos precedentes. Ou seja, com a necessidade da aplicação do stare decisis no momento da análise para que uma decisão venha a se tornar um precedente, percebe-se um elemento com força vinculante para todo o sistema, o qual não está previsto na lei local, mas sim na tradição. Pois para a efetiva criação de um precedente a análise da ratio decidendi e o obter dictum devem ser analisadas.

Pois bem, neste momento adentra-se o campo das súmulas, as quais são inerentes ao sistema Civil Law. Logo é essencial estabelecer de pronto que súmulas e precedentes não são a mesma coisa. 


\subsection{SÚMULA VINCULANTE X PRECEDENTE}

Aqui se fala especificamente em súmulas vinculantes, aquelas editadas pelo Supremo Tribunal Federal que necessitam de uma séria interpretação do direito para que possam ter força vinculante. E pensar que editar súmulas vinculantes através de uma interpretação qualquer e relativista do direito é gerar precedentes, é um grande equívoco.

Streck faz uma crítica ao efeito vinculante atribuído ao STF nas ações que declare inconstitucionalidade de normas, vejamos (2014, p. 723):

A primeira questão que ex-surge é a aparente novidade no sentido de que uma decisão que declare inconstitucionalidade - portanto, a invalidade - de uma lei tenha efeito vinculante. Ora, nada mais óbvio, sendo de estranhar que tenha sido necessário estabelecer legislativamente esse efeito. Hermeneuticamente, uma decisão que declara a inconstitucionalidade é uma decisão que "nadifica". Se uma lei é invalidada pelo Tribunal encarregado de dizer por último se uma lei é inconstitucional ou não, como admitir que alguém, juiz ou tribunal, pudesse dizer o contrário? E sobre o que o juiz estaria julgando? Sobre algo que deixou de ser válido? Sobre uma lei írrita? Nenhuma? Portanto, nada mais lógico que o efeito vinculante em ação que declara a invalidade de um ato normativo.

Da mesma forma pode se dizer que há o efeito vinculante da declaração de constitucionalidade e inconstitucionalidade, e o autor conclui dizendo que (STRECK; 2014, p. 723724): "trata-se de coisas diferentes, tratadas de forma equivocada pelo legislador. Ou seja, enquanto a declaração de nulidade importa a cassação da lei, não dispõe a declaração de constitucionalidade de efeito análogo.".

Com toda essa novidade em que a emenda constitucional 45 trouxe ao ordenamento jurídico brasileiro, percebe-se que com a prerrogativa do STF em interpretar a lei conforme achar pertinente, ocorre uma espécie de alteração da interpretação da norma e até mesmo uma alteração da própria mutação constitucional, (esta, advinda do direito alemão) onde nem sempre é observada a constitucionalidade dessas alterações.

É cristalino que há a necessidade de interpretação da norma e dos casos em concreto para que os efeitos vinculantes dessas decisões possam surtir, e aqui não se fala que todas as decisões dos tribunais superiores não devem ser levadas em conta, o que se fala é que a lei deve ser observada e minuciosamente analisada antes de decisões com efeito erga omnes sejam lançadas ao ordenamento jurídico.

Se faz necessário que o controle de constitucionalidade difuso e concentrado sejam distintos, visto que ambos se diferenciam em seu objeto, forma de análise da lei e ainda seus efeitos. A doutrina defensora da aplicação dos precedentes no Estado brasileiro, tem defendido que controle difuso e concentrado de constitucionalidade deve ser visto como um só instituto. Contudo, há de se perceber que tal pensamento é contrário a Constituição. Deste modo, explica José Afonso da Silva (SILVA, 2013, p. 51):

O controle político é o que entrega a verificação da inconstitucionalidade a órgãos de natureza política, tais como: o próprio Poder Legislativo, solução predominante na Europa no século passado; ou um órgão especial, como o Presidium do Soviete Supremo da ex- União Soviética (Constituição da URSS, art. 121, n. ${ }^{\circ}$ ) e o Conseil Constitutionnel da vigente Constituição 
francesa de 1958 (arts. 56 a 63). 0 controle jurisdicional, generalizado hoje em dia, denominado judicial review nos Estados Unidos da América do Norte, é a faculdade que as constituições outorgam ao Poder Judiciário de declarar a inconstitucionalidade de lei e de outros atos do Poder Público que contrariem, formal ou materialmente, preceitos ou princípios constitucionais.

As duas formas de controle de constitucionalidade não devem ser equiparadas. Streck (2014, p. 58) chama essa teoria de igualar o controle difuso e concentrado de "objetivação do controle difuso", pois "(...) ela carrega a ideia de que o STF e o STJ não julgam lides" e "suas atuações seriam tão somente objetivas". E conclui que (STRECK, 2014, p. 58) "(...) na realidade, a chamada objetivação permite ao STF fazer o que ele quiser, inclusive afastar-se do texto constitucional.".

O fato de que os tribunais superiores estejam disponíveis apenas para atuar de forma objetiva não encontra compatibilidade com a Constituição e tal fato não poderia ocorrer nem mesmo com mudança do texto constitucional pois os Tribunais Superiores, STF e STJ, seriam transformados em tribunais apenas para analisar remédios constitucionais, ou seja, mandado de segurança, habeas corpus, mandado de injunção e habeas data, logo, perderia a função jurisdicional de solução de controvérsias, não somente através dos recursos especial e extraordinário, mas também a função de atuar no controle de constitucionalidade concentrado e defesa da Constituição Federal.

Tanto a súmula quanto o precedente são um texto que se foi dado um sentido advindo de um caso em concreto, assim (STRECK; 2011, p. 368):

(...) consequentemente, haverá sempre um grau de generalização a ser extraído do núcleo da decisão, que fará a ligação hermenêutica (compromissos discursivos) com os casos que serão analisados em sua individualidade, promovendo o surgimento de novas normas na medida em que os novos casos forem surgindo.

Portanto, Streck $(2014$, p. 61) conclui que: “(...) isso quer dizer que a norma que surge "desse caso concreto" é, no momento seguinte, também um texto, do qual exsurgirá uma nova norma.".

O fato que diferencia a súmula dos precedentes do Common Law é que a súmula não é editada para resolver apenas um caso concreto, assim como é realizado no Common Law, onde o precedente visa primeiramente resolver o caso em análise, mas a súmula visa a resolução de todos os casos futuros, e não um caso específico que se encontra em apreciação, portanto, deve ser vista como um texto normativo.

Portanto, em um sistema que adota o Civil Law, como é o caso do Brasil, não é relevante que o Poder Judiciário possua a prerrogativa de legislar e atribuir interpretação a norma conforme sua convicção. Se faz muito necessário a séria análise do direito a ser feita antes da edição de súmulas vinculantes e até mesmo dos precedentes, oriundos do sistema Common Law.

Outra distinção de bastante relevância feita por Streck é que não há razões para comparar de forma segura que o Common Law é melhor que o Civil Law, como parte da doutrina defensora dos precedentes entende ser. Também simplesmente não se pode afirmar meramente que o Common Law é melhor que o Civil Law porque um sistema jurídico de determinado país funciona melhor que o sistema jurídico no Brasil. É preciso analisar todos 
os pontos relevantes e históricos de cada país para entender seu funcionamento jurídico. 0 que se pode afirmar diante de tal colocação de acordo com Streck (2014, p. 91) é que: "(...) em regra, na Alemanha ou na Inglaterra, as decisões judiciais talvez sejam melhores que a nossa.". Logo, o que importa não é necessariamente o sistema jurídico de cada país, mas sim, a qualidade das decisões judiciais.

Portanto, para análise da qualidade das decisões no Brasil, não é relevante que se faça essa análise somente comparado ao sistema jurídico Common Law, é importante também analisar pautado em outros países que adotam o próprio sistema Civil Law, como é o caso da Alemanha. Deste modo, pode-se ter conclusões mais precisas das decisões realizadas no Brasil, visto a igualdade dos sistemas jurídicos, mesmo cada um com suas peculiaridades próprias. Por fim, conclui o autor (STRECK; 2014, p. 93) que: “(...) argumentar por lei ou por precedente não assegura, por si só, uma resposta hermeneuticamente autêntica.".

\subsection{NOVO CÓDIGO DE PROCESSO CIVIL E O AVANÇO DA HERMENÊUTICA DO DIREITO}

Há quem defenda que o sistema de precedentes foi implementado no Novo Código de Processo Civil, com o argumento que com isso gerará mais igualdade e segurança jurídica. Contudo, Streck (2016, s/p) cita que "mediante a criação de instrumentos de vinculação decisória, o que faz parecer que essa doutrina ignora que a própria Constituição e a legislação que lhe é conforme vinculam efetivamente a atuação do Judiciário antes de tudo. E não o contrário.".

Para Streck (2016, s/p) o CPC 2015 não traz um sistema de precedentes pautado no sistema Common Law, ele traz são "(...) provimentos judiciais vinculantes cuja função é reduzir a complexidade judicial para enfrentar o fenômeno brasileiro da litigiosidade repetitiva. Respostas antes das perguntas. Mas, não podemos equiparar o artigo 927 a um sistema de precedentes, sob pena de termos uma aplicação desvirtuada do CPC.". Ou seja, devem ser lidos como provimentos judiciais, com efeitos vinculantes sem apresentar maiores complexidades nos casos em que se apresentarem semelhantes.

Através da análise realizada até o momento, em que pese ser certo dizer que no judiciário brasileiro existe muito protagonismo judicial e a discricionariedade exercida pelos juízes é imensa, Streck considera a necessidade de reconhecer que houve avanços no advento do NCPC, sob à luz da teoria da Crítica Hermenêutica do Direito. Pode se ter como o principal avanço trazido através de proposta de Streck, a extinção do livre convencimento nas decisões judiciais. 0 autor considera que tal retirada foi uma "conquista hermenêutica".

Vários eram os dispositivos no projeto do NCPC que tratavam sobre a livre apreciação do juiz, as quais foram extintas sob a justificativa que (Streck; 2016, p.148-149):

embora historicamente os Códigos Processuais estejam baseados no livre convencimento e na livre apreciação judicial, não é mais possível, em plena democracia, continuar transferindo a resolução dos casos complexos em favor da apreciação subjetiva dos juízes e tribunais. Na medida em que o Projeto passou a adotar o policentrismo e coparticipação no processo, fica evidente que a abordagem da estrutura do Projeto passou a poder ser lida como um sistema não mais centrado na figura do juiz. As partes assumem 
especial relevância. Eis o casamento perfeito chamado "coparticipação", com pitadas fortes do policentrismo. E o corolário disso é a retirada do "livre convencimento". O livre convencimento se justificava em face da necessidade de superação da prova tarifada. Filosoficamente, o abandono da fórmula do livre convencimento ou da livre apreciação da prova é corolário do paradigma da intersubjetividade, cuja compreensão é indispensável em tempos de democracia e de autonomia do direito. Dessa forma, a invocação do livre convencimento por parte de juízes e tribunais acarretará, a toda evidência, a nulidade da decisão.

Tal justificativa foi aceita pela Câmara, visto o fato de que não se pode mais elaborar códigos que possa o Estado ser visto como um inimigo do cidadão. Desta forma, com a retirada do dispositivo que o Código trazia sobre o livre convencimento do juiz, é retirado dos tribunais um pouco da discricionariedade da decisão limitando os juízes a proferir decisões conforme acharem pertinente, ou seja, o juiz deve decidir com base em razões.

É visto que é impossível lidar tanto com súmulas tanto com precedentes sem o elemento interpretativo. Porém, não se pode dizer qualquer coisa sobre qualquer coisa (STRECK; 2014, p. 113), “(...) interpretação é aplicação; é assentar sentidos. Os sentidos não são aleatórios. Não há grau zero. Há uma cadeia interpretativa que nos vincula. Tanto no cotidiano como no direito.". Logo, com a coerência e seriedade considerada nas interpretações, conclui-se que há uma interpretação vinculativa, independente se for súmula, lei e precedentes.

Assim, voltando brevemente a análise dos avanços hermenêuticos no CPC/2015, não há que se negar que houve um salto para uma visão não solipsista das decisões judiciais. Mas isso não quer dizer que o CPC não poderia ser melhor desenvolvido.

Diante dessa breve análise realizada da conquista hermenêutica, o que se pode concluir até o momento de modo geral é que o sistema Common Law não é melhor que o sistema Civil Law; há uma grande discricionariedade no Poder Judiciário no Brasil; súmulas vinculantes e precedentes não devem ser confundidos; texto e norma também não são a mesma coisa, e a hermenêutica coesa se faz necessária nas decisões dos tribunais brasileiros.

Portanto, a hermenêutica se faz necessária na análise de casos, principalmente aqueles no Supremo Tribunal Federal, e é obvio que conforme se apresenta as decisões atualmente, o Brasil encontra-se no sentindo contrário ao sistema Common Law. Deste modo, nas palavras de STRECK (2014, p. 373): “Hermenêutica é experiência. É vida! É este o nosso desafio: aplicá-la no mundo da vida!"

\section{CONSIDERAÇÓES FINAIS}

O Supremo Tribunal Federal é um tribunal em que sua principal finalidade é guardar a Constituição e respeitar os seus ditames legais. Logo, não há em que se falar que o STF é um tribunal que está direcionado a criar as leis, mas sim decidir conforme o que the é expresso. É óbvio que a interpretação deve ser realizada, mas não com base no solipsismo, fenômeno em que os juízes decidem conforme sua opinião, conforme já abordado por STRECK. 
Para uma análise concisa e séria muito importante se faz além de tudo, entender a sistemática dos sistemas jurídicos Commom Law e Civil Law, e cada uma das peculiaridades apresentadas nos países que adotam um desses sistemas. No Brasil, há quem defenda que a aplicação dos precedentes oriundos do Common Law, seja a melhor alternativa para as controvérsias levadas ao judiciário, porém, por outro lado, se faz indispensável realizar uma análise pautada na hermenêutica das decisões proferidas pelos tribunais.

No tocante a relação entre precedente e súmula vinculante, conforme mencionado, não podem ser confundidos e equiparados, visto a necessidade do precedente precisar dos requisitos pautados na doutrina stare decisis e apreciar primeiramente o caso em análise, e a súmula vinculante estar destinada a resolução de todos os casos futuros, e não um caso específico que se encontra em apreciação, portanto, deve ser vista como um texto normativo.

Assim, não há parâmetros seguros para se afirmar que o sistema Common Law é melhor que o Civil Law, pois cada um possui suas peculiaridades próprias e se adequam conforme a necessidade do ordenamento jurídico de cada país, através de seus movimentos históricos e culturais. Logo, o que importa não é necessariamente o sistema jurídico adotado em si, mas sim, a qualidade das decisões judiciais.

Portanto, os tribunais brasileiros, em específico o Supremo Tribunal Federal, necessita usar da prerrogativa que detém, defender a Constituição Federal e utilizar os mecanismos que lá se encontram para agir de forma justa perante a sociedade, e não achar que "fazer justiça" é colocar sua opinião conforme os ministros acharem mais pertinentes nas decisões em que lhe competem apreciar e justificar que é "para o bem da sociedade" decidir um caso totalmente ao contrário de suas decisões passadas, as quais supostamente já foram pacificadas, e principalmente decidir contra a Carta maior do Estado.

Desta forma, não haverá sistema jurídico que sustente tantas controvérsias fundamentadas em nada, o que consequentemente ao invés de como os defensores dos precedentes no Brasil alegam que com a aplicação dos mesmos haverá mais segurança jurídica, não haverá segurança alguma, ao passo que a praxe que vem sendo praticada nos tribunais brasileiros é de modificar algo que já está decidido e positivado.

Portanto, em que pese todo o estudo, ainda há questionamento a serem feitos a respeito da (não) evolução dos precedentes judiciais no Estado brasileiro, tais como: como defender uma segurança jurídica que se movimenta ao contrário da Constituição Federal e até mesmo da real essência e aplicação dos precedentes judicias oriundos do Common Law?! E ainda: ao invés de tentar trazer os precedentes judicias para dentro do sistema Civil Law, por que não primeiramente aprimorar as bases legais e hermenêuticas existentes dentro de nosso próprio ordenamento jurídico? Bom, talvez essa seja outra questão a ser estudada de forma profunda, visto a necessidade de uma séria análise hermenêutica a ser realizada.

\section{REFERÊNCIAS}

APPIO, Eduardo. Controle difuso de constitucionalidade: modulação dos efeitos, uniformização de jurisprudência e coisa julgada. Curitiba: Juruá, 2009. 
ATAIDE JR, Jaldemiro Rodrigues de. Uma proposta de sistematização da eficácia temporal dos precedentes diante do projeto de novo CPC. O projeto do Novo Código de Processo Civil. Estudos em homenagem ao Professor José Joaquim Calmon de Passos (Coord. Fredie Didier e Antonio Adonias Aguiar Bastos). Salvador: Juspodivm, 2012.

BARBOSA, Ruy. Cartas de Inglaterra: O Congresso e a Justiça no Regimen Federal. 2. Ed. São Paulo: Livraria Acadêmica Saraiva \& C., 1929.

BARROSO, Luís Roberto; MELLO, Patrícia Perrone Campos. Trabalhando com uma nova lógica: A ascensão dos precedentes no direito brasileiro. Disponível em: https://www.conjur.com.br/dl/artigo-trabalhando-logica-ascensao.pdf. Acesso em 01 jul. 2018.

, Luís Roberto. Curso de direito constitucional contemporâneo: os conceitos fundamentais e a construção do novo modelo. 4. ed. São Paulo: Saraiva, 2013.

BBC Brasil. Com. Perfil: John Roberts. Disponível em: https://www.bbc.com/portuguese/reporterbbc/ story/2005/09/050929_robertsperfilba.shtml. Acesso em 10 jun. 2018.

BRASIL. Constituição da República Federativa do Brasil, de 05 de outubro de 1988. Planalto Presidência da República. Disponível em: http://www.planalto.gov.br/ccivil_03/constituicao/constituicao.htm. Acesso em: 08 jul. 2018.

. Lei $n^{\circ}$ 13.105/Código de Processo Civil, de 16 de março de 2015. Planalto Presidência da República. Disponível em: http://www.planalto.gov.br/ccivil_03/_ato2015-2018/2015/lei/l13105.htm. Acesso em: 08 jul. 2018.

ENCYCLOPEDIA BRITANNICA. Plessy v. Ferguson. Disponível em: https://www.britannica.com/event/Plessy-v-Ferguson-1896. Acesso em 20 jun. 2018.

FARNSWORTH. E. Allan. An Introduction to the Legal System of the United States. Published for the Parker School of Foreign and Comparative Law Columbia University in the City of New York: Oceana Publications, Inc. 1963.

GODOY. Arnaldo Sampaio de Moraes. Direito nos Estados Unidos. Barueri, SP. Manole, 2004.

GRAU, Eros Roberto. Ensaio e discurso sobre a interpretação: aplicação do direito. 4. ed. São Paulo: Malheiros, 2006.

KELSEN, Hans. Teoria Pura do Direito. Trad. João Baptista Machado. 6ª ed. São Paulo. Martins Fontes, 1998.

MACIEL. Adhemar Ferreira. O acaso, John Marshall e o controle de constitucionalidade. Senado Federal. Brasília, a.43, n.172, p. 37-44 out./dez. 2006. p. 40. Disponível em: https://www2.senado.leg.br/bdsf/bitstream/handle/ id/93276/Maciel\%20Adhemar.pdf. Acesso em 23 jul. 2018.

MARINONI, Luiz Guilherme. Precedentes obrigatórios. 3. ed. Rev. atual. e ampliada. São Paulo: Editora Revista dos Tribunais, 2013.

, Luiz Guilherme; MITIDIERO, Daniel. Ratio Decidendi e Obtier Dicta. In: SARLET, Ingo Wolfgang. Curso de Direito Constitucional. São Paulo: Editora Revista dos Tribunais, 2012.

MELLO, Patrícia Perrone Campos. Precedentes Vinculantes nos Estados Unidos da América e no direito brasileiro: um estudo comparado. Disponível em: http://corteidh.or.cr/tablas/r25603.pdf. Acesso em 20 jun. 2018.

SARLET, Ingo Wolfgang. Curso de Direito Constitucional. São Paulo: Editora Revista dos Tribunais, 2012.

SILVA, José Afonso da. Curso de Direito Constitucional Positivo. 36. ed. São Paulo: Malheiros, 2013.

STRECK, Lenio Luiz. Hermenêutica jurídica e $(m)$ crise: uma exploração hermenêutica da construção do Direito. 11. ed. rev., atual. e ampl. Porto Alegre: Livraria do Advogado Editora, 2014.

Lenio Luiz. Jurisdição Constitucional e decisão jurídica. 4. ed. São Paulo: Revista dos Tribunais, 2014.

, Lenio Luiz; ABBOUD, Georges. O que é isto - o precedente judicial e as súmulas vinculantes?. 2. ed. Revi. Atua. Porto Alegre: Livraria do Advogado Editora, 2014.

, Lenio Luiz; ABBOUD, Georges. Senso incomum - 0 que é isto - o sistema (sic) de precedentes no CPC? Disponível em: https://www.conjur.com.br/2016-ago-18/senso-incomum-isto-sistema-sic-precedentes-cpc. Acesso em: 21 jul. 2018. 
, Lenio Luiz. Uma Análise Hermenêutica dos Avanços Trazidos pelo Novo CPC. Revista Estudos Institucionais. Rio de Janeiro, v.2, n. 3, p. 144-167, jul. 2016.

Lenio Luiz. Verdade e Consenso. 4. ed. São Paulo: Saraiva, 2011.

WAMBIER, Teresa Arruda Alvim. Sobre a Súmula 343. RePro. São Paulo: RT, v. 22, n. 86, p. 148-157, abri./jun/ 1997.

Teresa Arruda Alvim; e outros coordenadores. Breves comentários ao Novo Código de Processo Civil. São Paulo: Editora Revista dos Tribunais, 2015.

Recebido/Received: 24.03.2020.

Aprovado/Approved: 12.06.2020. 